\title{
IMPACTO DA EMENDA CONSTITUCIONAL № 45/2004 NO PODER JUDICIÁRIO TRABALHISTA
}

\author{
IMPACT OF CONSTITUTIONAL AMENDMENT NO 45/2004 ON THE JUDICIARY \\ LABOR
}

\author{
Naíma Worm ${ }^{1}$, Mariama Rezende Mendonça ${ }^{2}$
}

\begin{abstract}
RESUMO
O trabalho expressa a proposta de apresentar os principais impactos da Emenda Constitucional no 45/2004 na estrutura e funcionamento do Poder Judiciário Trabalhista. A pesquisa não esgotará todas as alterações promovidas pela emenda, mas apresentará aquelas que repercutiram efeitos internos e externos no judiciário trabalhista, desde de a relação entre seus órgãos e servidores, bem como a ampliação da matéria de competência da justiça trabalhista. Para isso, partimos do ideal de repartição do poder em três funções distintas - Legislativo, Executivo e Judiciário - até alcançar o modelo apresentado pela Constituição Cidadã de 1988, com poderes independentes e harmônicos entre si. Após, apontaremos as modificações trazidas pela emenda constitucional que impactaram a justiça do trabalho. Por fim, concluímos que as alterações otimizaram a justiça trabalhista, trazendo mais celeridade e acesso ao jurisdicionado. Ainda, concluímos como crítica à emenda, que ela poderia ter levado à justiça trabalhista os litígios que envolvem os servidores estatutários. A metodologia aplicada é a utilização da pesquisa de referencial bibliográfico, com levantamento das teorias aplicadas à questão e estudo da Emenda Constitucional no 45/2004.
\end{abstract}

Palavras - chave: Emenda Constitucional n. 45/2004; Justiça do Trabalho; impactos da Emenda Constitucional n. 45/2004; competência material da Justiça do Trabalho.

\footnotetext{
ABSTRACT

The work expresses the proposal to present the main impacts of Constitutional Amendment No. 45/2004 on the structure and functioning of the Labour Courts. The survey did not exhaust all the changes introduced by the amendment, but present those that have affected internal and external effects on the labor judiciary, since the relationship between its organs and servers as well as the expansion of the jurisdiction of the labor courts. For this, we start from the power division of ideal in three distinct functions - legislative, executive and judicial - to achieve the model presented by the Citizen Constitution of 1988, with independent powers and

${ }^{1}$ Doutoranda em Direito Político e Econômico na Universidade Presbiteriana Mackenzie. Mestre em Direito Político e Econômico na Universidade Presbiteriana do Mackenzie. Docente-pesquisadora da Universidade Federal do Tocantins (UFT). Realiza pesquisas sobre o tema Políticas Públicas de Drogas, direitos humanos e Direito Constitucional. E-mail.naima@mail.uft.edu.br

${ }^{2}$ Possui graduação em Direito pela Fundação Universidade Federal do Tocantins (2015). Atualmente trabalha como advogada autônoma e presta assistência jurídica a entidades do terceiro setor.
} 
harmonious among themselves. After, we will point out the changes brought about by the constitutional amendment that impacted the labor courts. Finally, we conclude that the changes optimized the labor courts, bringing more speed and access to the claimants. Still, we conclude as critical to the amendment, it could have led to labor courts in disputes involving statutory servers. The methodology applied is the use of bibliographic references of research, a survey of the theories applied to the issue and study of Constitutional Amendment 45/2004.

Key words: Constitutional Amendment. 45/2004; Work justice; impacts of Constitutional Amendment. 45/2004 in the labor courts; material competence of the labor courts.

\section{CONSIDERAÇÕES INICIAIS}

A Emenda Constitucional n 45/2004 provocou reformas profundas no Poder Judiciário, impactando diretamente a seara trabalhista. O Presente artigo tratará das modificações geradas pela emenda e os reflexos nos procedimentos com trâmite na Justiça do Trabalho.

Inicialmente far-se-á uma explanação acerca do modelo de separação de poderes, consolidado por Montesquieu, para a partir dessa perspectiva compreender as regras que asseguram a autonomia e independência dos poderes.

O Poder Judiciário sofreu profundas reformas a partir da Emenda Constitucional no 45/2004, que promoveu mudanças no seu modo de funcionamentos e trouxe alguns institutos que visam celeridade no atendimento aos jurisdicionados. Exemplo a criação do Conselho Nacional de Justiça, que atua na fiscalização do próprio poder judiciário, e as súmulas vinculantes, que uniformizam a jurisprudência, vinculando Poder Judiciário e Administração Pública.

Ainda, a referida emenda mudou a competência material da Justiça do Trabalho, ampliando o rol de ações com propositura na Justiça do Trabalho. Assim, todos os aspectos relacionados à relação de trabalho, quando em estado de conflito, serão levados à apreciação da justiça trabalhista. 


\section{A SEPARAÇÃO dOS PODERES E O FORTALECIMENTO DO PODER JUDICIÁRIO COM A CONSTITUIÇÃO DE 1988}

A Constituição de 1988 inaugurou uma nova ordem de direitos no cenário jurídico brasileiro, inspirada em princípios que revelam a influência dos direitos humanos no país.

As instituições se fortaleceram a partir do novo texto, ganhando mais autonomia e mecanismo de proteção das suas funções. Com o Poder Judiciário o processo de (re)construção foi o mesmo: fortalecimento das carreiras - Magistrados e serventuários, ampliação dos princípios que protegem o exercício da jurisdição e garantem maior acesso à justiça.

A ideia de repartição de competência das funções estatais remonta à Antiguidade, com Aristóteles, que nos seus estudos sobre a política condenava a concentração de poderes em uma só pessoa e defendia que o governo deveria ser constituído por três funções: a legislativa, executiva e judiciária. Outros importantes estudos também foram desenvolvidos na Idade Média e Idade Moderna acerca da separação dos poderes.

Distinguira Aristóteles a Assembleia -geral, o corpo de magistrados e o corpo judiciário; Marsílio de Pádua no Defensor Pacis já percebera a natureza das distintas funções estatais e por fim, a Escola de Direito Natural das Gentes, com Grotius, Wolf e Puffendorf, ao falar em partes potentiales summi impeii, se aproximara bastante da distinção estabelecida por Montesquieu. (BONAVIDES, 2010, p. 136).

Paulo Bonavides discorrendo acerca da teoria de Locke, pensador inglês, explica que a obra do filósofo foi marcada pela oposição ao absolutismo, assinalando a distinção entre os três poderes - Legislativo, Executivo e Judiciário, remontando a uma quarta forma de expressão, o poder de prerrogativa, que conferia ao governante agir conforme suas atribuições e julgamentos, desde que pautados na ideia de justiça. "Ao fazê-lo, seu pensamento é mais autenticamente vinculado à Constituição Inglesa do que o do autor de Do Espírito das Leis" (BONAVIDES, 2010, p. 136).

Montesquieu inaugura uma nova forma de ver a distribuição dos poderes, que deixa de ser uno para dividir-se em três, consagrando o ideal liberal de não 
concentração do poder na figura dos monarcas absolutistas. Apesar da controvérsia que gira em torno da sua indicação da Inglaterra como modelo da separação de poderes, tendo em vista que no período que o filósofo político visitou o país, já havia uma inclinação para o modelo parlamentarista, no qual os poderes legislativo e executivo governam de maneira interdependente, a sua obra deixa claro que a divisão do poder evita o autoritarismo e abuso por parte dos governantes.

Ainda sobre Montesquieu, (s/d, p. 407) propõe "em cada Estado três sortes de poderes: o poder legislativo, o poder executivo (poder executivo das coisas que dependem do direito das gentes, segundo sua terminologia) e o poder judiciário (poder executivo das coisas que dependem do direito civil)". Os poderes são notadamente marcados pela liberdade de atuação, independência no exercício das suas funções. (MONTESQUIEU, s/d, p. 407 apud BONAVIDES, 2011, p. 138-139.

A primeira constituição brasileira, editada ainda no período imperial - 1824, previa a existência de quatro poderes: legislativo, executivo, judiciário e moderador. Os três primeiros com as funções de legislar, administrar e julgar, enquanto que ao Imperador cabia o Poder Moderador, situado sobre os demais poderes e marcado pelo unitarismo e centralização do exercício do poder.

Nas palavras de José Afonso da Silva (2009, p. 78-79):

Rompera com a divisão quadripartita no Império de Benjamin Constant, para agasalhar a doutrina tripartita de Montesquieu, estabelecendo como "órgãos da soberania nacional o Poder Legislativo, Executivo e o Judiciário, harmônicos e independentes entre si.

A tripartição dos poderes veio com a segunda constituição brasileira, de 1891, a Constituição do Brasil República, com o modelo de administração descentralizado na federação e o exercício do poder dividido em três esferas: Poder Legislativo, Poder Executivo e Poder Judiciário.

Desse marco histórico em diante todas as demais constituições repetiram o modelo de descentralização do poder, com momentos de fragilidade, a exemplo dos regimes ditatoriais de Getúlio Vargas (1937) e o regime Militar (1964), em que o Poder Legislativo foi esvaziado, com o fechamento de muitas das suas casas e o Poder Judiciário teve cerceada suas garantias funcionais e institucionais. O ideal de convivência harmônica e independente entre os três poderes é exercício constante das democracias, que utilizam em sua maioria dos textos constitucionais para impor 
limites e mecanismos assecuratórios das suas atribuições, a denominada teoria dos freios e contrapesos.

A independência e autonomia dos poderes são características relativas e limitadas, pois faz parte dos poderes o sistema de controle recíproco a fim de que nenhum extrapole suas atribuições e tente subjugar outro poder, o que permite constatar que nenhum é plenamente independente, em razão do exercício simultâneo das funções típicas e atípicas.

A teoria dos freios e contrapesos permite um abrandamento da rígida separação de poderes estabelecida por Montesquieu, permitindo uma maior interpenetração de um poder em outro. Assim, um poder participa das funções típicas de outro poder por meio do exercício de atribuições que para si são atípicas, mas para o outro típicas. Alguns exemplos ilustram bem: o julgamento do Presidente da República por crime de responsabilidade no Congresso Nacional, a elaboração de Regimentos Internos pelos Tribunais, dentre outros.

Assim, o Poder Judiciário [...] administra seus órgãos e servidores e legisla ao expedir regulamentos.

O Poder Legislativo [...] julga o Presidente da República e ministros de Estado em crimes de responsabilidade, bem como os ministros do Supremo Tribunal Federal e membros dos Conselhos Nacionais de Justiça e do Ministério Público, Procurador Geral da República e o Advogado Geral da União, nos crimes de responsabilidade (art. 52, I e II, CRB/88). Administra ao dispor sobre a organização, política e provimento de SUS cargos (arts. 51, IV e 52, XIII, CRB/88).

O Poder Executivo legisla: edita medidas provisórias (art. 62, $\mathrm{CRB} / 88$ ) e o Presidente da República pode elaborar leis delegadas (arts. 59, IV e $68 \mathrm{CRB} / 88$. Julga inúmeros pedidos de administrados, estruturando, inclusive, jurisdição administrativa", no âmbito interno da administração pública (PELEJA JúNIOR, 2011, p. 85).

A Constituição da República Federativa de 1988 inaugurou uma nova ordem de mecanismos de segurança às funções institucionais dos poderes, sendo que ao Poder Judiciário, por intermédio de seu órgão de cúpula o Supremo Tribunal Federal, cabe a tarefa de proteger a Constituição e assim evitar o desvirtuamento das suas finalidades maiores, dentre elas resguardar a democracia e os direitos fundamentais.

O art. $2^{\circ}$ da CRFB/88, estabelece que "São Poderes da União, independentes e harmônicos entre si, o Legislativo, o Executivo e o Judiciário", uma cláusula pétrea, nos termos do art. $60, \S 4^{\circ}$, da CRFB/88. 
Ao Poder Judiciário foi dada uma configuração estrutural que possibilitasse garantir com a máxima presteza o acesso à justiça e um processo célere, fundado em princípios maiores que si próprio. Ocorre que ao longo dos anos, como efeito da ampliação do acesso à justiça e intensificação dos conflitos em sociedade, tornouse, o judiciário, moroso na resposta jurisdicional e encastelado nos seus órgãos e repartições, demandando com urgência uma nova roupagem, que lhe trouxesse dinamicidade e poder maior de fiscalização.

Sem inovar tanto na estrutura, mas fortalecido quanto ao exercício das suas prerrogativas constitucionais, o Poder Judiciário teve fixado sua organização no art. 92 da CRFB/88, apresentando a divisão por matéria, em Justiças Especializadas trabalhista, eleitoral e militar - e Justiça Comum - federal e estadual. A Emenda Constitucional n 45/2004 criou o Conselho Nacional de Justiça, órgão do Poder Judiciário com a responsabilidade de fiscalização.

São órgãos do Poder Judiciário: (EC nº 45/2004)

I - o Supremo Tribunal Federal;

I-A o Conselho Nacional de Justiça; (Incluído pela Emenda Constitucional ํㅜ 45, de 2004)

II - o Superior Tribunal de Justiça;

III - os Tribunais Regionais Federais e Juízes Federais;

IV - os Tribunais e Juízes do Trabalho;

V - os Tribunais e Juízes Eleitorais;

VI - os Tribunais e Juízes Militares;

VII - os Tribunais e Juízes dos Estados e do Distrito Federal e Territórios.

$\S 1^{\circ}$ O Supremo Tribunal Federal, o Conselho Nacional de Justiça e os Tribunais Superiores têm sede na Capital Federal. (Incluído pela Emenda Constitucional no 45, de 2004)

$\S 2^{\circ}$ O Supremo Tribunal Federal e os Tribunais Superiores têm jurisdição em todo o território nacional. (Incluído pela Emenda Constitucional ํㅜ 45, de 2004)

Ponto importante refere-se à autonomia do Poder Judiciário para gerir-se administrativa e financeiramente, por meio de comandos constitucionais que lhe garantam independência aos seus magistrados e autonomia financeira e gerencial.

A CRFB/88 contemplou, no art. 95, garantias funcionais aos juízes, com a seguinte redação:

I - vitaliciedade, que, no primeiro grau, só será adquirida após dois anos de exercício, dependendo a perda do cargo, nesse período, de deliberação do tribunal a que o juiz estiver vinculado, e, nos demais casos, de sentença judicial transitada em julgado; 
II - inamovibilidade, salvo por motivo de interesse público, na forma do art. 93, VIII;

III - irredutibilidade de vencimentos, observado, quanto à remuneração, o que dispõem os arts. 37, XI, 150, II, 153, III, e 153, § $2^{2}$, I.

III - irredutibilidade de subsídio, ressalvado o disposto nos arts. 37, $\mathrm{X}$ e XI, 39, § 4ํㅜㄴ $150, \mathrm{II}, 153$, III, e 153, § $2^{\circ}$, I.

Ainda, assegurou nos termos do art. 99 autonomia administrativa e financeira ao Poder Judiciário, sendo que os Tribunais Superiores elaboram suas propostas orçamentárias observando as diretrizes estabelecidas na Lei de Diretrizes Orçamentárias e são encaminhadas ao Executivo, para fins de consolidação.

A independência externa ou orgânica do Poder Judiciário diz respeito à maneira como elabora a gestão administrativa, com receitas orçamentárias e financeiras disponíveis, compatíveis as necessidades. Trata-se do autogoverno, englobando a independência administrativa, orçamentária e financeira (PELEJA JÚNIOR, 2011).

A independência do Judiciário, incluídas as garantias conferidas aos seus membros, sem a qual os magistrados não teriam liberdade para aplicar a lei, controlar os atos do governo, inclusive de constitucionalidade, consiste em pressupostos para a existência desse poder e garantia da aplicação dos direitos.

[...] essa liberdade - como segurança - não se encontraria presente se o executivo e o legislativo fossem um só corpo, mas também se o judiciário não estive separado dos dois, pois, em caso contrário, haveria um juiz opressor.

[...] acolhida a separação, ninguém mais terá constantemente, os juízes diante dos olhos, passando-se a temer - frase de efeito - a magistratura e não os magistrados[...].

O sentido de lei de Montesquieu é muito mais rico do que qualquer ato produzido pelo legislativo, razão por que se deve entender o juiz invisível e nulo, como um juiz imparcial, vinculado que está ao direito mais do que o texto preciso de lei como hoje compreendemos - e não às suas opiniões pessoais, para poder gerar o sentimento comum de segurança [...] (SAMPAIO, 2007, p. 119).

Com esse espírito o Poder Legislativo finaliza em 2004 uma ampla reforma no texto constitucional, que culminou com importantes alterações em todo o judiciário, a exemplo da criação do Conselho Nacional de Justiça, órgão do próprio Poder Judiciário com a função de fiscalização e correição desse poder. 


\section{OS PRINCIPAIS PONTOS DA REFORMA PROMOVIDA PELA EMENDA CONSTITUCIONAL № 45/2004 E OS IMPACTOS NO PODER JUDICIÁRIO TRABALHISTA}

A reforma trabalhou aspectos internos do Poder Judiciário, de organização dos seus órgãos, e fatores externos, que tocam aos jurisdicionados e aos processos em si próprio. Aqui buscaremos tratar dos aspectos relacionados à sua organização e as modificações implementadas pela Emenda Constitucional ㄲo 45/2004.

A estrutura da Justiça do Trabalho está definida no art. 111, CRFB/88 sendo constituída por órgãos da Justiça Trabalho - I - o Tribunal Superior do Trabalho; II os Tribunais Regionais do Trabalho; III - Juízes do Trabalho. O texto constitucional referiu-se às pessoas dos juízes e não às varas do trabalho, sendo que essas não são órgãos da Justiça Trabalho, fazendo parte da estrutura administrativa, local em que o magistrado exerce a sua atividade judicante.

O Juiz do trabalho exerce a jurisdição trabalhista em primeira instância, sendo que, nos termos do art. 112 da CRFB, os municípios não abrangidos pela competência dos órgãos da Justiça do Trabalho, a jurisdição trabalhista será exercida pelo Juiz de Direito. Nessa hipótese os recursos serão endereçados aos Tribunais Regionais do Trabalho, e não aos Tribunais de Justiça, como ocorre na justiça comum estadual.

Com relação aos Tribunais Regionais do Trabalho, originalmente o texto constitucional dispunha que deveriam existir ao menos um tribunal em cada unidade da Federação, a fim de garantir o pleno acesso ao jurisdicionado. Todavia, hoje são 24 Tribunais, sendo que a emenda constitucional no 45/2004 modificou a redação, não chegando a ser criados nos Estados do Tocantins, Acre, Roraima e Amapá. Para mitigar essa situação de barreira ao acesso à justiça, o texto trouxe dois instrumentos: criação de Câmaras Regionais e Justiça itinerante, a fim de facilitar o acesso ao duplo grau de jurisdição. Os Estados supra citados dirigem seus recursos ao TRT da 1ำ Região, com sede em Brasília.

O último grau da jurisdição trabalhista será exercido no Tribunal Superior do Trabalho, composto por 27 Ministros, com sede em Brasília e jurisdição em todo o território nacional.

Trataremos das principais alterações trazidas na emenda, comentando os dispositivos que refletiram mudanças na organização do Poder Judiciário e que 
refletiram na justiça do trabalhista.

Com relação à a razoável duração do processo, O artigo 5, LXXVIII da CRFB/88 "a todos, no âmbito judicial e administrativo, são assegurados a razoável duração do processo e os meios que garantam a celeridade de sua tramitação" trouxe importante ordem de celeridade aos processos vitimados pela leniência do sistema jurídico, sob a ideia que justiça tardia pode-se refletir em injustiça. $O$ comando constitucional serviu de subsídio para que o Conselho Nacional, também criado pela emenda com as funções de fiscalização e correição, pudesse estabelecer metas de julgamento, com o propósito de pôr a fim processos antigos.

A Justiça do Trabalho possui o adjetivo de ser uma justiça célere e simplificada, com um poder de resposta ágil às demandas envolvendo as relações de trabalho. Hoje o trâmite processual ocorre informatizado, proporcionando celeridade sem perder a qualidade nos julgados.

No âmbito da legislação, a emenda trabalhou a constitucionalização dos tratados e convenções internacionais sobre direitos humanos, desde que

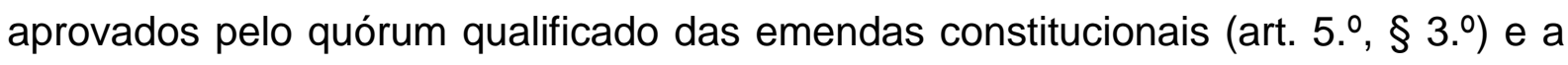
submissão do Brasil à jurisdição do Tribunal Penal Internacional (TPI) a cuja criação tenha manifestado adesão (art. 5. ${ }^{\circ}, \S 4 .^{\circ}$ ). Até o presente apenas o Tratado de Nova York, que trata de direitos das pessoas com deficiências foi recebido com status de norma constitucional, sinalizando para uma era de direitos humanos internacionais inserido no contexto local com força normativa. Trata-se de uma valorização dos direitos humanos e demais princípios protetivos já constitucionalizados pelo texto de 1988, inclusive os de ordem trabalhista, valorizando em âmbito constitucional a proteção ao trabalho.

A criação do Conselho Nacional de Justiça representou importante avanço ao Poder Judiciário no sentido de fiscalização e correição dos seus atos, subordinando o poder a um órgão criado no seu âmbito com funções de fiscalização das funções. O Supremo Tribunal Federal sempre repudiou o controle do Judiciário por órgãos externo, sob pena de violação da separação dos poderes.

Observa -se, então, que o STF repudia não só a interferência de outros Poderes ou entidades no controle do Judiciário como, também, qualquer atividade externa que atente contra a garantia de autogoverno dos Tribunais e a autonomia administrativa, financeira e orçamentária, prescritas nos arts. 96, 99 e $\S \S$, e 168 da CF, que, segundo fixou a Suprema Corte, são corolários do princípio da 
separação de Poderes, erigido, conforme já exposto, à categoria de

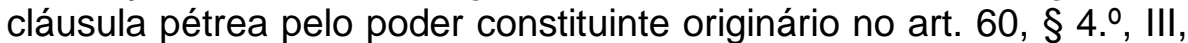
que nem sequer admite qualquer proposta tendente a aboli -lo. (LENZA, 2013, p. 790).

Assim, mesmo sob forte resistência inicial, o Conselho Nacional de Justiça iniciou o exercício das suas funções de fiscalização e correição, zelando no exercício das suas funções pela autonomia do poder sem perder de vista o dever de cumprimento das funções constitucionalmente estabelecidas. A criação desse órgão representa um dos pontos mais importantes da emenda.

Ao ser inserido na estrutura do Poder Judiciário, o Conselho Nacional de Justiça foi objeto de muitas discussões, tendo como principal alegação a violação da independência dos Poderes. Recebida com críticas a criação do CNJ, a Associação dos Magistrados Brasileiros manejou uma Ação Direta de Inconstitucionalidade, argumento que feria os arts. $2^{\circ}$ e 18 , da CRFB/88. Contudo, o Supremo Tribunal Federal, por maioria de votos julgou improcedente a ação e declarou constitucional o órgão, pondo fim à celeuma sobre sua constitucionalidade e à própria legitimidade para existir.

Mesmo sob forte resistência dos opositores ao Conselho, especialmente de membros do próprio Poder Judiciário, o Conselho Nacional de Justiça vem ao longo desses 11 anos desenvolvendo um trabalho importante para viabilizar o acesso à justiça e tem a função de:

Realizar o controle da atuação administrativa e financeira do Poder Judiciário e do cumprimento dos deveres funcionais dos juízes, estabelecendo constitucionalmente, porém de forma exemplificativa, suas mais importantes atribuições, que poderão ser acrescidas pelo Estatuto da Magistratura (MORAES, 2014, p. 521).

De acordo com Bulos (2011. p. 1329), "O Conselho Nacional de Justiça exerce a sua competência constitucional por meio de moções, atas, resoluções, portarias, notas técnicas, recomendações, enunciados administrativos e termos de cooperação técnica".

Assim, trata-se de um órgão criado no sentido de conferir fiscalização do Poder Judiciário sobre si próprio a fim de evitar desvios e corrosão dos seus órgãos e julgados.

Outra importante inovação advinda com a emenda são as Súmulas Vinculantes. Trata-se de um instituto introduzido no ordenamento jurídico brasileiro, 
que adicionou o art. 103-A à Constituição Federal de 1988. correspondem à tentativa de adaptação do modelo anglo-saxônico, o stare decisis, da expressão "mantenhase a decisão e não se perturbe o que foi decidido" (stare decisis et quieta non movere), para o sistema brasileiro romano-germânico civil law (Bulos, 2011).

Alexandre de Morais salienta:

As súmulas vinculantes surgem a partir da necessidade de reforço à idéia de uma única interpretação jurídica para o mesmo texto constitucional ou legal, de maneira a assegurar-se a segurança jurídica e o princípio da igualdade, pois os órgão do poder judiciário não devem aplicar as leis e atos normativos aos casos concretos de forma a criar ou aumentar desigualdades arbitrárias, devendo, pois, utilizar-se de todos os mecanismos constitucionais no sentido de conceder às normas jurídicas uma interpretação única e igualitária. (2009, p. 566).

Para Bulos (2011, p. 1311), as súmulas vinculantes correspondem ao instrumento que "permite ao Supremo Tribunal Federal padronizar a exegese de uma norma jurídica controvertida, evitando insegurança e disparidade de entendimento em questões idênticas".

Nas palavras de Kildare Gonçalves Carvalho "As súmulas são concisos enunciados que, de maneira objetiva, explicitam a interpretação de tribunal a respeito de determinada matéria". (2008, p. 522)

As súmulas vinculantes são aplicadas à Justiça do Trabalho da mesma forma que se aplicam aos demais órgãos do Poder Judiciário, verticalizando as decisões tomadas em última instância para as demais, no sentido de uniformizar o entendimento do Judiciário sobre questões já discutidas e consolidadas no Supremo Tribunal Federal.

Com relação à matéria de competência da Justiça do trabalho, a Emenda trouxe para o âmbito dessa justiça especializada tudo que se refere às relações de trabalho:

Art. 114.Compete à Justiça do Trabalho processar e julgar:

I as ações oriundas da relação de trabalho, abrangidos os entes de direito público externo e da administração pública direta e indireta da União, dos Estados, do Distrito Federal e dos Municípios;

II as ações que envolvam exercício do direito de greve;

III as ações sobre representação sindical, entre sindicatos, entre sindicatos e trabalhadores, e entre sindicatos e empregadores;

IV os mandados de segurança, habeas corpus e habeas data, quando o ato questionado envolver matéria sujeita à sua jurisdição; 
$\mathrm{V}$ os conflitos de competência entre órgãos com jurisdição trabalhista, ressalvado o disposto no art. 102, I, o;

$\mathrm{VI}$ as ações de indenização por dano moral ou patrimonial, decorrentes da relação de trabalho;

VII as ações relativas às penalidades administrativas impostas aos empregadores pelos órgãos de fiscalização das relações de trabalho; VIII a execução, de ofício, das contribuições sociais previstas no art. 195, I, a , e II, e seus acréscimos legais, decorrentes das sentenças que proferir;

IX outras controvérsias decorrentes da relação de trabalho, na forma da lei.

A competência da Justiça do trabalho "foi ampliada, no sentido de abranger não só os litígios derivados da relação de emprego, mas todos aqueles derivados da relação de trabalho, sem necessidade de autorização expressa em lei. (CAIRO, JÚNIOR, 2012. P. 132-133).

Para Sérgio Pinto Martins (2012, p. 110), "Trabalho é o esforço decorrente da atividade humana visando à produção de uma utilidade. É um fator de produção." Trata-se da finalidade da atividade econômica que tem por escopo gerar riqueza e desenvolvimento econômico e social. A relação de trabalho decorre do próprio conceito de trabalho, compreendendo todos os fatos que envolvem trabalhador e tomador do trabalho.

Relação de trabalho é a relação jurídica entre o trabalhador e o tomador de serviços, que pode ser física ou intelectual, com ou sem remuneração. Contrato de trabalho é o negócio jurídico firmado entre empregado e empregador sobre condição de trabalho. (MARTINS, 2012, p. 110).

O objetivo é que toda a matéria oriunda da relação de trabalho, a partir da emenda constitucional n 45/2004, seja discutida no âmbito da Justiça do trabalho, e não apenas a relação de emprego, como sugeria a redação original.

Com relação às questões pertinentes à relação de trabalho entre servidores públicos e a administração pública, o justiça competente será a comum, por se tratar de uma competência oriunda de uma relação jurídica estatutária, não contratual. A nosso ver há uma impropriedade na interpretação, pois a Justiça do trabalho já é competente para julgar os dissídios resultantes da relação entre empregados públicos celetistas e administração pública, possuindo excelência e um bom aparelhamento para julgar as ações de natureza estatutária.

Importante inovação foi a previsão de justiça itinerante e a sua 
descentralização trouxe consigo a urgência de se rever os mecanismos que asseguram o duplo grau de jurisdição em um país com dimensões continentais, no qual a distância dificulta o acesso aos Tribunais Regionais e Superiores.

Esses são alguns dos pontos da reforma do judiciário, que direta e indiretamente repercutiram efeitos na Justiça do trabalho. Agora passaremos a tratar das alterações feitas na emenda que repercutiram efeitos na organização e competência das ações julgadas no âmbito da justiça trabalhista.

\section{CONSIDERAÇÕES FINAIS}

A emenda Constitucional n 45/2004 é fruto de mais de uma década de esforço dos Poderes Legislativo e Judiciário em reformar o sistema que dá aporte ao Poder Judiciário Brasileiro, no sentido de conferir celeridade e equilíbrio no exercício da função jurisdicional.

A presente discussão teve por objetivo apresentar os principais impactos que a reforma causou no Poder Judiciário Trabalhista, que dentro do sistema judiciário brasileiro merece respeito pela celeridade e qualidade empenhadas na função da prestação jurisdicional. A reforma ampliou seu campo de ação, trazendo para o bojo das suas atribuições julgar todas as questões pertinentes à relação de trabalho.

De acordo com a clássica tripartição de poderes, desenhada por Montesquieu, as três funções do poder estão intimamente ligadas entre si, mantendo autonomia e independência um em relação ao outro. Esse desenho de poder evita o abuso e autoritarismo, típico quando ocorre a concentração em uma única esfera. $A$ Constituição é responsável por esse arranjo político, traçando os limites e controle de um poder sobre o outro.

Dentro desse sistema, o Poder Judiciário ganhou novo fôlego com a emenda Constitucional no 45/2004, que o impactou tanto internamente, na relação entre seus órgãos, como externamente, na relação com o jurisdicionado.

A Justiça do Trabalho possui a peculiaridade de lidar com uma relação frágil e naturalmente desproporcional, no qual o empregador possui mais meios para atingir seus objetivos processuais que o trabalhador. Assim, cabe a essa justiça a difícil tarefa de aplicar os princípios que possibilitam uma paridade entre as partes na lide processual.

Dentre todas as inovações tratadas no texto, a emenda criou o instituto das as 
súmulas vinculantes frente à necessidade de maior celeridade da atividade jurisdicional por meio da uniformização da jurisprudência. A questão gerou controvérsias quando da sua edição, sob o argumento que poderia engessar o Poder Judiciário. Esse argumento ainda persiste e é latente nas discussões sobre a liberdade de julgamento das causas. A nosso ver o referido instituto proporciona rapidez no julgamento de questões já pacificadas no Judiciário e que acelerarão o julgamento de demandas idênticas.

Outro importante impacto da emenda foi a criação do Conselho Nacional de Justiça, que possibilitou maior controle administrativo e financeiro do Judiciário sobre seus órgãos e atuação dos seus membros, possibilitando um canal aberto às reclamações dos usuários do sistema.

Por fim, a emenda impactou desde a ampliação do conteúdo das matérias que serão julgadas pela Justiça Trabalhista, como a criação de institutos que diretamente influenciaram no modo de operacionalização da justiça.

\section{REFERÊNCAS}

BRASIL. Constituição da república federativa do Brasil de 1988. Disponível em $<$ http://www.planalto.gov.br/ccivil 03/constituicao/ConstituicaoCompilado.htm>. Acesso em 09 set. 2015.

BONAVIDES, Paulo. Curso de Direito Constitucional. 25 ed. atual. São Paulo: Malheiros Editora Ltda, 2010.

BULOS, Uadi Lammêgo. Curso de Direito Constitucional 6. ed. rev. atual.São Paulo: Editora Saraiva, 2010.

CAIRO JUNIOR, José. Curso de direito processual do trabalho. 5 ed. Bahia: JusPodivm, 2012.

CARVALHO, Kildare Gonçalves. Direito Constitucional. 14. ed. Rev. Atual e Ampl. Belo Horizonte: Del Rey, 2008.

FERREIRA FILHO, Manoel Gonçalves. Curso de Direito Constitucional. 36 ed., rev. e atual. de acordo com a Emenda Constitucional no 64/2010. São Paulo: Editora Saraiva, 2010.

MARTINS, Sergio Pinto. Direito do Trabalho. São Paulo: 28 ed. Atlas, 2012.

MORAES, Alexandre de. Direito Constitucional. 30 ed, atualizada até EC no 56/2006. São Paulo: Editora Atlas, 2014. 
PELEJA JÚNIOR, Antonio Veloso. Conselho Nacional da Magistratura brasileira. 2 ed. rev e atual. Curitiba: Juruá, 2011.

SAMPAIO, José Adércio Leite. Conselho Nacional de Justiça e a Independência do Judiciário. Belo Horizonte: Del Rey, 2007. 